\title{
Awareness and Attitude of Moroccan Orthodontics Regarding Professionalism
}

\author{
Hakima Aghoutan ${ }^{*}$, Lamia Bouchghel ${ }^{1}$, Wijdane Benmiloud ${ }^{2}$, Farid El Quars ${ }^{1}$ \\ ${ }^{1}$ Department of Orthodontics, Faculty of Dentistry, Hassan II University Casablanca, Casablanca, Morocco \\ ${ }^{2}$ Private Dental Practice, Casablanca, Morocco \\ Email: ^hakimaaghoutan.2014@gmail.com
}

How to cite this paper: Aghoutan, H., Bouchghel, L., Benmiloud, W. and El Quars, F. (2021) Awareness and Attitude of Moroccan Orthodontics Regarding Professionalism. Open Access Library Journal, 8: e8238.

https://doi.org/10.4236/oalib.1108238

Received: November 27, 2021

Accepted: December 20, 2021

Published: December 23, 2021

Copyright (c) 2021 by author(s) and Open Access Library Inc.

This work is licensed under the Creative Commons Attribution International License (CC BY 4.0).

http://creativecommons.org/licenses/by/4.0/

\begin{abstract}
Introduction: To assess orthodontists' perception of professionalism, identify the constraints encountered, and draw attitudes to improve the professionalism of the dentist profession, we conducted a survey of orthodontists in the private sector of the city of Casablanca, Morocco. Methods: This is a descriptive cross-sectional survey of 200 practitioners using a questionnaire that provided information on socio-demographic characteristics and summarized the perception and attitude of orthodontists towards the main components of the medical professionalism charter. The statistical analysis was carried out according to descriptive and analytical modalities. The chi2, or Fisher's exact tests were used to compare different qualitative variables. The significance level was set at 0.05 . Results: The response rate was $87.5 \% .85 .1 \%$ of participants did not have education about professionalism. 35.4\% defined this concept as clinical competence and know-how. $66.3 \%$ are convinced that collaboration with other specialists is essential for improving the quality of care. A total of $76.6 \%$ of orthodontists respected the patient's right to information and thus the use of free and informed consent before starting treatment. $48.6 \%$ of orthodontists participated in prevention campaigns and $33.1 \%$ had social actions. On the other hand, duration and exclusivity of orthodontic practice were significantly associated with work-life balance, informing the patient in case of medical error, and use of practice organization software. While life-long education and knowledge of the concept of evidence-based practice were influenced by exclusive orthodontic practice (respectively $\mathrm{p}=$ 0.039 and $p=0.047$ ). The personal development activity was significantly associated with gender $(\mathrm{p}=0.0243)$. Conclusion: Similar to these results, gaps in the knowledge of dentists in terms of professionalism resulting from a lack of training in this area were noted. Dentists are anxious about promoting their professional image and the quality of the relationship with their patients and society as a whole through a teaching of professionalism that must now
\end{abstract}


be integrated into the pre- and post-university curriculum.

\section{Subject Areas}

Dentistry

\section{Keywords}

Orthodontists, Professionalism, Perception, Attitude

\section{Introduction}

In the dental literature, professionalism has been described as an important aspect of competence. It is an essential skill that enables health care workers to perform their duties, adhere to ethical principles, and demonstrate sensitivity to a diverse patient population [1] [2] [3]. These themes, which revolve around honesty, integrity, respect, and commitment to high standards of practice, are included in the definitions of professionalism of a number of medical regulatory bodies, including the General Medical Council in the United Kingdom, the Accreditation Council for Graduate Medical Education in the United States, and the Association of Canadian Medical Colleges [4]. There may not be a universally accepted definition of the term "professionalism" [5], although we often feel we have an innate understanding of it [6]. Most therefore agree on the need to assess behaviors in context [7]. However, to have an effective assessment and remediation process, standards of professionalism must be explicit, teaching methods must inspire learners, and programs must ensure that students and physicians value the assessment of professionalism [8] [9].

The objective of this study was to assess orthodontists' perception of professionalism in order to learn about the constraints and the attitudes needed to improve it.

\section{Methods}

To accomplish this work, we conducted a descriptive cross-sectional study of a population of orthodontists in the city of Casablanca, Morocco. The practitioners were classified by district and determined on the basis of the telecontact directory. We opted for this approach after having consulted the office of the southern regional council of the national order of dentists. Due to the absence of an official database of privately practicing orthodontists, probability sampling could not be undertaken. Therefore, a convenience sample based on the response of the dentists contacted was used. We included dentists in Casablanca practicing in the private sector whose practice included orthodontics, while dentists specializing exclusively in disciplines other than orthodontics were excluded.

Our sample was made up of 200 orthodontists. A questionnaire distributed 
presents a synthesis of the charter of professionalism elaborated by the American Board of Internal Medicine Foundation, the American College of Physicians Foundation, and the European Federation of Internal Medicine [10], the message of the president of the Canadian Medical Association [11], and the flowchart evoked in a survey on the professionalism of Taiwanese student physicians (Figure 1) [12].

The questionnaire consists of two main parts: the first part is about identification, and the second one is about evaluation of different components of professionalism.

Independent variables related to identification were represented by:

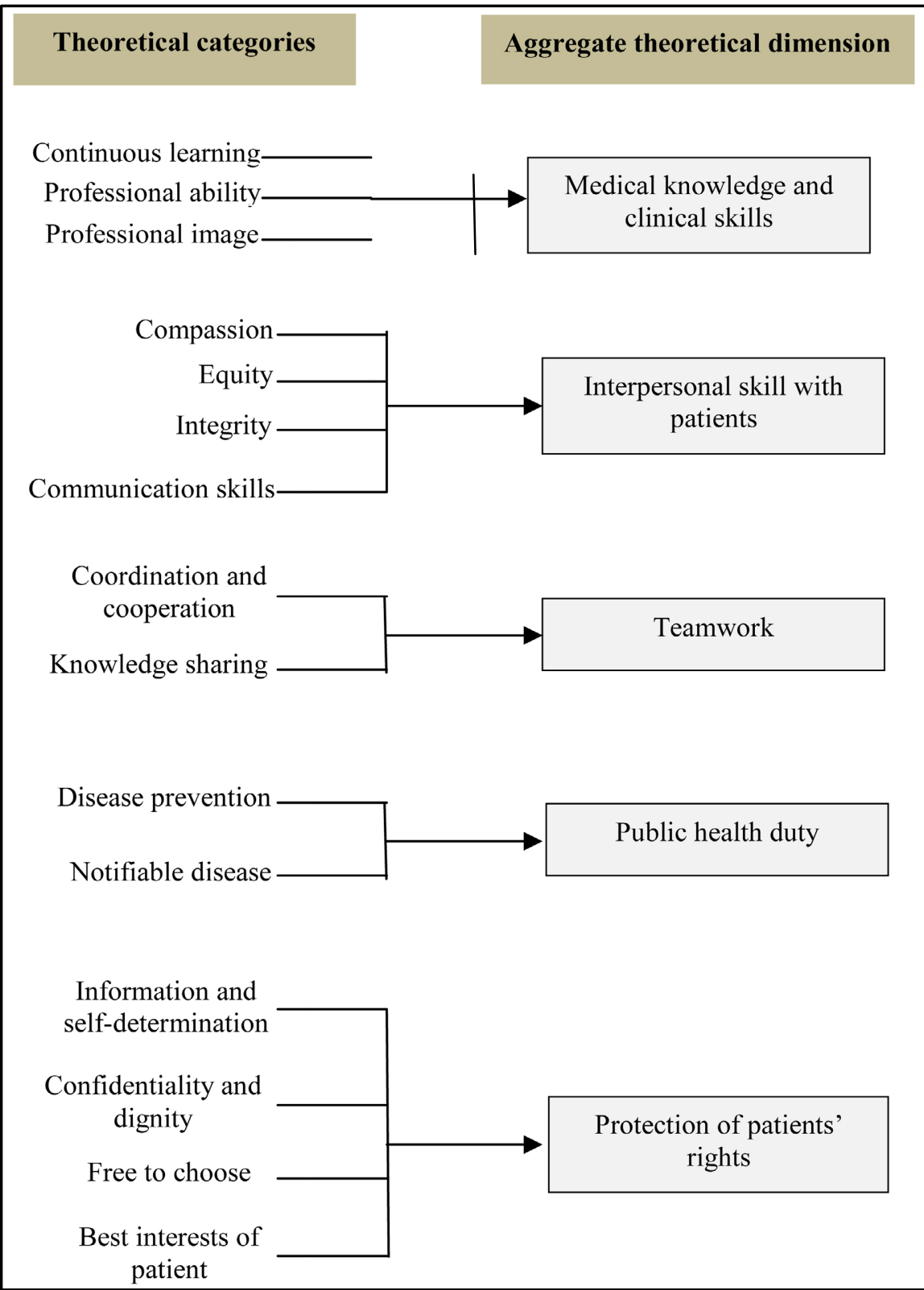

Figure 1. The flow chart of ideal dimensions of professionalism. (Survey of Taiwanese medical students) [12]. 
- Age, number of years of orthodontic practice, which are quantitative variables.

- Gender, exclusive orthodontic practice, which are qualitative variables.

Dependent variables related to the components of professionalism were:

- Definition of professionalism

- Perception towards Teaching of professionalism during medical school

- Work-life balance

- Medical knowledge, life-long education and clinical skills

- Teamwork

- Interpersonal skills with patients

- Time management, availability and willingness to evaluate performance

- Ethics/Protection of patients' rights

- Public health duty

The survey was conducted from February to April.

\subsection{Difficulties and Biases}

We tried to overcome the difficulties encountered and to avoid bias that would alter the value of our results. Nevertheless, we were confronted with some difficulties. The list of orthodontists was not available at the national order, some orthodontists refused to answer, there was difficulty in locating some addresses, and there was the absence of e-mail addresses of some practitioners.

\subsection{Statistical Analysis}

Data creation and processing were performed in Epiinfo software version 3.4.5., an interoperable tool designed for public health practitioners and researchers. The statistical analysis of the results was carried out according to two descriptive and analytical modalities.

The qualitative variables are described by numbers and percentages, and the quantitative variables were dichotomized for better interpretation. The chi2 test, or Fisher's exact test when the conditions for applying the previous one were not met, was used to compare different qualitative variables. The significance level was set at 0.05 .

\section{Results}

After contacting 200 physicians, 175 responded, for a response rate of $87.5 \% .83$ male $(47.4 \%)$ and 92 female (52.6\%) were included. 36\% were 18 - 34 years old, $60.6 \%$ were 35 - 54 years old, and $3.4 \%$ were 55 or older. A total of $37.1 \%$ of dentists performed orthodontic specialization in Morocco, and 62.9\% have done so abroad. $26.9 \%$ of dentists have been in practice for more than 10 years and $22.9 \%$ were exclusive orthodontists.

Table 1 summarizes the different definitions of professionalism presented by study participants. Moreover, $93.7 \%$ of dentists felt that their daily orthodontic practice allows them to be professional. 
Table 1. Definitions of professionalism presented by study participants.

\begin{tabular}{lc}
\hline \multicolumn{1}{c}{ Professionalism Definition } & Frequency (\%) \\
\hline No answer & 29.71 \\
Clinical competence and know-how, Good therapeutic choice & 31.43 \\
Honesty and rigor & 6.86 \\
Perfection & 6.86 \\
Specialty & 6.29 \\
Ethics & 4.57 \\
Effectiveness and efficiency & 2.86 \\
Updating knowledge & 2.86 \\
Good patient-practitioner relationship & 2.86 \\
Respect of the limits of competence & 2.86 \\
Punctuality and time management & 1.14 \\
How to be & 1.14 \\
Good practitioner-colleague relationship & 0.57 \\
Total & 100.00 \\
\hline
\end{tabular}

The dentists' perception of the integration of professionalism education into basic training according to gender, age, duration of orthodontic practice, and exclusive orthodontic practice are shown in Table 2.

In addition, $66.3 \%$ are convinced that collaboration with other specialists is essential for improving the quality of care. A total of $76.6 \%$ of orthodontists respected the patient's right to information and thus the use of free and informed consent before starting treatment. $64 \%$ were honest with their patients in case of medical error and $96.9 \%$ have never disclosed the confidentiality of their patients. $20.6 \%$ had completed continuing education on ethics. $48.6 \%$ of orthodontists participated in prevention campaigns and $33.1 \%$ had social actions. $60 \%$ of dentists have a prevention slot in their practice. It is provided by: the assistant (24.6\%), the doctor himself (34.9\%), and a specialized hygienist (0.6\%).

Considering attitudes towards therapeutic difficulty, 53.1\% searched the literature, $65.7 \%$ asked for help from a colleague, $27.4 \%$ explained the problem to the patient and referred him/her to another specialist, and $19.4 \%$ tried to treat the patient anyway. $90.3 \%$ of dentists participate in medical congresses and $50.9 \%$ have a subscription to scientific journals or databases.

When faced with a patient dissatisfied with a colleague's treatment, $24.6 \%$ contacted the previous practitioner, $35.4 \%$ managed the patient as a new case, $40.6 \%$ asked the patient to retrieve all medical records from the previous practitioner, and $17.1 \%$ refused the patient's care.

Likewise, in case of a complication in a patient followed by a colleague, $25.7 \%$ of dentists did not mention the problem and treated it as a new case. $4.6 \%$ explained the complication to the patient as medical malpractice committed by the 
Table 2. Perception of the integration of professionalism education according to gender, age, duration of orthodontic practice and exclusive orthodontic practice.

\begin{tabular}{|c|c|c|c|c|c|c|c|}
\hline & & \multicolumn{5}{|c|}{ Integration of professionalism education } & \multirow{2}{*}{$\mathrm{P}$ value } \\
\hline & & Optional & Mandatory & Desirable & Useful & Total & \\
\hline \multirow{3}{*}{ Gender } & Women & 1 & 47 & 28 & 16 & 92 & \multirow{3}{*}{0.240} \\
\hline & Men & 4 & 33 & 32 & 14 & 83 & \\
\hline & Total & 5 & 80 & 60 & 30 & 175 & \\
\hline \multirow{4}{*}{$\begin{array}{c}\text { Age } \\
\text { (Years) }\end{array}$} & $18-34$ & 0 & 35 & 19 & 9 & 63 & \multirow{4}{*}{0.462} \\
\hline & $35-54$ & 5 & 42 & 38 & 21 & 106 & \\
\hline & $>54$ & 0 & 3 & 3 & 0 & 6 & \\
\hline & Total & 5 & 80 & 60 & 30 & 175 & \\
\hline \multirow{4}{*}{$\begin{array}{c}\text { Duration of } \\
\text { orthodontic } \\
\text { practice } \\
\text { (Years) }\end{array}$} & $5-10$ & 2 & 25 & 29 & 9 & 65 & \multirow{4}{*}{0.116} \\
\hline & $<5$ & 0 & 35 & 17 & 11 & 63 & \\
\hline & $>10$ & 3 & 20 & 14 & 10 & 47 & \\
\hline & Total & 5 & 80 & 60 & 30 & 175 & \\
\hline \multirow{3}{*}{$\begin{array}{c}\text { Exclusive } \\
\text { orthodontic } \\
\text { practice }\end{array}$} & No & 4 & 66 & 43 & 22 & 135 & \multirow{3}{*}{0.458} \\
\hline & Yes & 1 & 14 & 17 & 8 & 40 & \\
\hline & Total & 5 & 80 & 60 & 30 & 175 & \\
\hline
\end{tabular}

other practitioner and treated it. $20.6 \%$ of dentists contacted the previous practitioner for further explanation. $44 \%$ referred to the complication as an inherent part of the orthodontic practice without incriminating the former practitioner and treated it. $21.1 \%$ refused to treat the patient. There was no significant statistical association with this attitude and age, gender, duration or exclusivity of orthodontic practice.

On another note, $56.6 \%$ of respondents use practice management software and $20 \%$ have conducted a patient satisfaction survey.

Tables 3-5 present the statistically significant results found between different components of professionalism and gender, duration and exclusivity of orthodontic practice.

Table 3 shows that women were less engaged in personal development activity than men. The difference was statistically significant $(\mathrm{p}<0.05)$.

Table 4 highlights that exclusive orthodontists used practice organization software more than general practitioners $(p=0.001)$. They informed their patients in case of medical error $(p=0.003)$ and were more involved in the continuing education process $(\mathrm{p}=0.039)$. A statistically significant association was also found between exclusive orthodontic practice on the one hand and knowledge of the concept of evidence-based practice and work-life balance on the other hand. The orthodontists were more aware of the evidence-based practice and more likely to have a better work-life balance (respectively $p=0.047$ and $p=0.001$ ).

Furthermore, we found that experienced orthodontists tended to use practice 
Table 3. Practice of a personal development activity according to gender.

\begin{tabular}{cccccc}
\hline & \multicolumn{3}{c}{ Personal development activity } & \multirow{2}{*}{ P value } \\
\cline { 2 - 5 } & Never & Rarely & Often & Always & \\
\hline Woman & 16 & 26 & 27 & 23 & 0,0243 \\
Man & 7 & 22 & 25 & 29 & \\
\hline
\end{tabular}

Table 4. Areas of professionalism significantly associated with the exclusive practice of orthodontics.

\begin{tabular}{|c|c|c|c|}
\hline & & \multicolumn{2}{|c|}{ Exclusive orthodontic practice } \\
\hline & & Yes & No \\
\hline \multirow{3}{*}{$\begin{array}{c}\text { Use of practice } \\
\text { organization software }\end{array}$} & Yes & 31 & 68 \\
\hline & No & 9 & 67 \\
\hline & $P$ value & \multicolumn{2}{|c|}{0.001} \\
\hline \multirow{3}{*}{$\begin{array}{l}\text { Informing the patient } \\
\text { in case of medical } \\
\text { error }\end{array}$} & Yes & 33 & 79 \\
\hline & No & 7 & 56 \\
\hline & $P$ value & \multicolumn{2}{|c|}{0.003} \\
\hline \multirow{4}{*}{$\begin{array}{l}\text { Inability to have a } \\
\text { work-life balance }\end{array}$} & Agree & 11 & 71 \\
\hline & Disagree & 12 & 27 \\
\hline & Neutral & 17 & 37 \\
\hline & $P$ value & \multicolumn{2}{|c|}{0.001} \\
\hline \multirow{3}{*}{ Life-long education } & Yes & 39 & 117 \\
\hline & No & 1 & 18 \\
\hline & $P$ value & \multicolumn{2}{|c|}{0.039} \\
\hline \multirow{3}{*}{$\begin{array}{c}\text { Evidence-based } \\
\text { practice knowledge }\end{array}$} & Yes & 22 & 52 \\
\hline & No & 18 & 83 \\
\hline & $P$ value & \multicolumn{2}{|c|}{0.047} \\
\hline
\end{tabular}

Table 5. Areas of professionalism significantly associated with the duration of orthodontic practice.

\begin{tabular}{ccccc}
\hline & & \multicolumn{2}{c}{ Duration of orthodontic practice (years) } \\
\cline { 3 - 5 } & & $<5$ & $5-10$ & $>10$ \\
\hline \multirow{2}{*}{$\begin{array}{c}\text { Use of practice } \\
\text { organization software }\end{array}$} & Yes & 30 & 34 & 35 \\
& P value & 33 & 31 & 12 \\
\hline $\begin{array}{c}\text { Informing the patient } \\
\text { in case of medical }\end{array}$ & Yes & 43 & $\mathbf{0 . 0 1 3}$ & 36 \\
error & No & 20 & 32 & 11 \\
\hline \multirow{2}{*}{$\begin{array}{c}\text { Inability to have a } \\
\text { work-life balance }\end{array}$} & P value & & 0.01 & 14 \\
& Agree & 35 & 35 & 19 \\
& Disagree & 8 & 12 & \\
\hline
\end{tabular}


organization software and to inform their patients of medical errors more than younger practitioners. They also seemed better able to find a work-life balance. The difference between $<5$ years, 5 - 10 years, and $>10$ years of experience was significant (Table 5).

\section{Discussion}

We conducted a unidirectional cross-sectional descriptive survey of 200 orthodontists in the private sector of the city of Casablanca, Morocco. The aim of our study was to evaluate the perception of private orthodontists in relation to professionalism, to identify the constraints in relation to professionalism, and to know the suitable attitudes to improve it.

1) Practitioner definition of professionalism and teaching professionalism. Clinical competence and know-how was the most mentioned component in the answers we received in our survey with a rate of $35.4 \%$ according to the different variables. This shows that the dentists interviewed limit professionalism to a closed circle of know-how without giving importance to the other components. Knowing how to do is associated with knowing how to be; an essential component of professionalism.

Unfortunately, "knowing how to be" was the least mentioned component in the responses received with a rate of $3.4 \%$.

A number of professional associations, dental schools and researchers in dentistry consider training on professionalism of great relevance for the future of dentistry [13]. In our sample, $50 \%$ of the dentists who are 55 years or older have already received education about professionalism during their medical studies. In contrast, $50 \%$ of younger dentists had or had not received education. This shows that perhaps the old medical school curricula had given importance to teaching professionalism. Instilling the principles of professionalism and garnering interest in assessment of the learning environment is currently a key focus of accrediting bodies and medical training programs [7]. 45.7\% of our dentists consider it mandatory to integrate a professionalism education program.

In New Zealand Professionalism is an integral part of patient care, but it is a core competency that, until 2016, was “sometimes lacking in student clinics" and is now independently assessed [14].

2) Work-life balance. Personal activities during the workweek renew energy and thus the ability to work and give one's best for the satisfaction of the patient and society. According to gender; $65.8 \%$ of male dentists always or often do personal development activities, and $57.1 \%$ of female dentists often or rarely do activities. The results of several studies suggest that burnout may erode professionalism, influence quality of care, increase the risk for medical errors, and promote early retirement [15] [16] [17].

3) Knowledge update. Attendance at medical conferences was $90.3 \%$ of our sample. $89.1 \%$ of the dentists attended continuing education courses on new developments in orthodontics. Orthodontics is a specialty in perpetual renewal. 
This fact was illustrated in our study by the scientific journals subscription among dentists ( $80 \%$ of the exclusive orthodontists and $42.2 \%$ of the general practitioners).

On the other hand, this survey revealed a rate of $66.7 \%$ of practitioners aged 18 - 24 years who are aware of the principle of Evidence based practice. This shows that the youngest have witnessed the integration of this principle into medical studies. Still, a program that allows for the teaching of professionalism in the first year must be established. According to students' individual understandings of professionalism, personalized learning may be introduced to meet the differing needs of students [1].

4) Attitudes towards a therapeutic difficulty. Our survey work revealed that $65.7 \%$ of practitioners seek help from a colleague and $19.4 \%$ try and meet the challenge by searching the literature. The results of Madhavji et al. confirm that when facing clinical uncertainties, orthodontists most often consulted colleagues and least often referred the patient to another orthodontist [18]. Whereas colleagues are a quick, inexpensive, and convenient source of advice, they can have biases and conflicts of interest [18] [19]. Ideally, clinicians should identify the best current evidence that can help guide decision-making process [20].

5) The practitioner-colleague relationship. In front of a patient treated by another colleague, $40.6 \%$ of our respondents request the medical records, $35.4 \%$ take charge of the patient as a new case, $24.6 \%$ contact the former practitioner and only $17.1 \%$ refuse to treat the patient. According to Article 58 public health code in France "The doctor consulted by a patient treated by one of his colleagues must, with the patient's agreement, inform the attending doctor and inform him of his findings and decisions. If the patient refuses, he must inform the patient of the consequences that may result from his refusal" [21].

6) Collaboration with other specialties. Our results reveal a rate of $66.3 \%$ of practitioners who work in collaboration with other specialists, and only $33.7 \%$ who are satisfied with their own skills. Collaboration with other specialties is essential in improving the quality of care, and must treat colleagues fairly and with respect, in all situations and all forms of interaction and communication [22].

7) Patient-practitioner relationship. The dentist-patient relationship is considered the most important application of professionalism [23], with two main components being a healing relationship and a caring relationship. In our sample, $76.6 \%$ always seek free and informed consent from the patient. $76 \%$ of dentists explain the treatment. And in case of a medical error, $64 \%$ of the doctors inform the patient. $41.1 \%$ of them regardless of the damage and $22.9 \%$ only if there is no significant damage. The physician must therefore spend time with patients to explain medical treatment, talk with the family as well as with the patients [23], and show empathy [23] [24]. A final aspect of professionalism with patients is appearance that significantly influenced patient comfort and anxiety levels [24].

8) Practice management. The survey work revealed that $56.6 \%$ of dentists 
use practice organization software and $20 \%$ of dentists have ever conducted satisfaction surveys in their practice. This shows that most practitioners overlook patient feedback or rely on word of mouth for client development.

It is therefore concluded that regardless of the type of career path, a graduating dentist would benefit from a leadership course [25]. Leadership training can be provided by teaching communication skills, staff and patient management, teamwork, and financial resource management in different practice management courses [26].

Like any professional, the dental assistant can undergo training that will benefit both the practitioner whose expertise she complements and the patients who are offered better care.

9) Ethics. Professionalism is a concept that informs how we should act, and as such, it belongs firmly in the realm of ethics [27]. Our survey revealed that $79.4 \%$ of practitioners had never received ethics training. $96.6 \%$ of practitioners felt they were ethical. But for most, competence and ethics is a matter of habit [28]. Adherence to ethical principles requires respecting patients' autonomy and right to choose as patients, prioritizing patients' interests, protecting the confidentiality of patient information; communicating effectively, providing good care and maintaining public trust [14]. Thus, medical ethics creates a specific attitude to improve the quality of patient care by identifying, analyzing, and resolving ethical issues that arise in practice [29].

\section{Conclusion}

Through this study, we were able to get an advance notice of the current state of professionalism as perceived by a population of orthodontists in Casablanca. The study showed that a significant number of dentists consider it mandatory to integrate a professionalism education program. However, another study with a larger and more representative sample of the orthodontic population on a national scale is needed to extrapolate the results and to make orthodontists aware of the importance of professionalism and to introduce its logic in their daily practice.

\section{Conflicts of Interest}

The authors declare no conflicts of interest.

\section{References}

[1] Cui, X., Ding, N., Jiang, N., Li, H. and Wen, D. (2021) Preliminary Study of the Relationship between Career Choice Motivation and Understanding of Professionalism in Newly Enrolled Medical Students in China: A Cross-Sectional Study. BMJ Open, 11, e041860. https://doi.org/10.1136/bmjopen-2020-041860

[2] Larkin, G.L., Binder, L., Houry, D. and Adams, J. (2002) Defining and Evaluating Professionalism: A Core Competency for Graduate Emergency Medicine Education. Academic Emergency Medicine, 9, 1249-1256. https://doi.org/10.1197/aemj.9.11.1249 
[3] Forouzadeh, M., Kiani, M. and Bazmi, S. (2018) Professionalism and Its Role in the Formation of Medical Professional Identity. Medical Journal of the Islamic Republic of Iran, 32, 130. https://doi.org/10.14196/mjiri.32.130

[4] Brennan, N., Price, T., Archer, J. and Brett, J. (2019) Remediating Professionalism Lapses in Medical Students and Doctors: A Systematic Review. Medical Education, $1-9$.

[5] Birden, H., Glass, N., Wilson, I., Harrison, M., Usherwood, T., et al. (2014) Defining Professionalism in Medical Education: A Systematic Review. Medical Teacher, 36, 47-61. https://doi.org/10.3109/0142159X.2014.850154

[6] Hook, H. and Woolley, J. (2021) A Consideration of Professionalism for Dental Professionals. Primary Dental Journal, 10, 69-72.

https://doi.org/10.1177/20501684211012587

[7] Byszewski, A., Gill, J.S. and Lochnan, H. (2015) Socialization to Professionalism in Medical Schools: A Canadian Experience. BMC Medical Education, 15, 204. https://doi.org/10.1186/s12909-015-0486-Z

[8] Zijlstra-Shaw, S., Roberts, T.E. and Robinson, P.G. (2013) Perceptions of Professionalism in Dentistry-A Qualitative Study. British Dental Journal, 215, E18. https://doi.org/10.1038/sj.bdj.2013.1048

[9] Passi, V., Doug, M., Peile, E., Thistlethwaite, J. and Johnson, N. (2010) Developing Medical Professionalism in Future Doctors: A Systematic Review. International Journal of Medical Education, 1, 19-29. https://doi.org/10.5116/ijme.4bda.ca2a

[10] American Board of Internal Medicine Foundation (ABIM) (2002) Medical Professionalism in the Millenium: A Physician Charter. Annals of Internal Medicine, 163, 668-669.

[11] Hall, J.L. (2016) Assessment of Professionalism in Family Medicine Residents: Turning the Mirror around. Canadian Family Physician, 62, 181.

[12] Chiu, C.H., Lu, H.Y., Arrigo, L.G., Wei, C.J. and Tsai, D. (2010) A Professionalism Survey of Medical Students in Taiwan. Journal of Experimental \& Clinical Medicine ( Taiwan), 2, 35-42. https://doi.org/10.1016/S1878-3317(10)60006-X

[13] Alcota, M., Manríquez, J.M., Cornejo-Ovalle, M., Salinas, J.C., Catano, V.M., et al. (2019) Values Related to Professionalism in Dental Education at the University of Chile: Student and Faculty Perceptions. European Journal of Dental Education, 23, 190-198. https://doi.org/10.1111/eje.12419

[14] Friedlander, L.T., Meldrum, A.M. and Lyons, K. (2019) Curriculum Development in Final Year Dentistry to Enhance Competency and Professionalism for Contemporary General Dental Practice. European Journal of Dental Education, 23, 498-506. https://doi.org/10.1111/eje.12458

[15] Dyrbye, L.N., Massie, F.S., Eacker, A., Harper, W., Power, D., et al. (2010) Relationship between Burnout and Professional Conduct and Attitudes among US Medical Students. JAMA, 304, 1173-1180. https://doi.org/10.1001/jama.2010.1318

[16] Shanafelt, T.D., Balch, C.M., Bechamps, G., Russell, T., Dyrbye, L., et al. (2010) Burnout and Medical Errors among American Surgeons. Annals of Surgery, 251, 995-1000. https://doi.org/10.1097/SLA.0b013e3181bfdab3

[17] Shanafelt, T.D., Boone, S., Tan, L., Dyrbye, L.N., Sotile, W., et al. (2012) Burnout and Satisfaction with Work-Life Balance among US Physicians Relative to the General US Population. Archives of Internal Medicine, 172, 1377-1385. https://doi.org/10.1001/archinternmed.2012.3199

[18] Madhavji, A., Araujo, E., Kim, K. and Buschang, P.H. (2011) Attitudes, Awareness, 
and Barriers toward Evidence-Based Practice in Orthodontics. American Journal of Orthodontics and Dentofacial Orthopedics, 140, 309-316. https://doi.org/10.1016/j.ajodo.2010.05.023

[19] Iqbal, A. and Glenny, A. (2002) General Dental Practitioners' Knowledge of and Attitudes towards Evidence Based Practice. British Dental Journal, 193, 587-591.

https://doi.org/10.1038/sj.bdj.4801634

[20] Yusof, Z.Y.M., Han, L.J., San, P.P. and Ramli, A.S. (2008) Evidence-Based Practice among a Group of Malaysian Dental Practitioners. Journal of Dental Education, 72, 1333-1342. https://doi.org/10.1002/j.0022-0337.2008.72.11.tb04616.x

[21] Article R.4127-58 of the French Public Health Code. https://www.conseil-national.medecin.fr/code-deontologie

[22] Standards for the Dental Team. Principle Six - Work with Colleagues in a Way That Serves the Interests of Patients. General Dental Council.

https://standards.gdc-uk.org/Assets/pdf/Standards\%20for\%20the\%20Dental\%20Tea m.pdf

[23] Krain, L.P. and Lavelle, E. (2009) Residents' Perspectives on Professionalism. Journal of Graduate Medical Education, 1, 221-224.

https://doi.org/10.4300/JGME-D-09-00064.1

[24] Watts, D.J. (2016) What Does Dental Professionalism Mean to You? Faculty Dental Journal, 7, 122-125. https://doi.org/10.1308/rcsfdj.2016.122

[25] Nazir, M.A., Izhar, F., Tariq, K., Anjum, K.M., Bin Sohailet, Z., et al. (2018) A Cross-Sectional Study of Dentists about the Need for a Practice Management Course in Undergraduate Dental Program. European Journal of Dentistry, 12, 508-515. https://doi.org/10.4103/ejd.ejd $184 \quad 18$

[26] Kalenderian, E., Skoulas, A., Timothé, P. and Friedland, B. (2010) Integrating Leadership into a Practice Management Curriculum for Dental Students. Journal of Dental Education, 74, 464-471. https://doi.org/10.1002/j.0022-0337.2010.74.5.tb04892.x

[27] Trathen, A. and Gallagher, J.E. (2009) Dental Professionalism: Definitions and Debate. British Dental Journal, 206, 249-253. https://doi.org/10.1038/sj.bdj.2009.164

[28] Ozar, D.T. (2012) Professionalism Challenges for Dentistry in the Future. Journal of Forensic Odonto-Stomatology, 30, 72-84.

[29] Khorshidian, A., Larijani, B., Ahmad-Akhoundi, M.S., Parsapour, A., Ebadi, A., et al. (2019) Design and Development of Dentistry Ethical Codes: Proposed for National Implementation in Iran. Frontiers in Dentistry, 16, 303-318. https://doi.org/10.18502/fid.v14i4.2090 